Marquette University

e-Publications@Marquette

4-1-2018

\title{
A visible geography of invisible journeys: Central American migration and the politics of survival
}

Noelle K. Brigden

Marquette University, noelle.brigden@marquette.edu

Published version. International Journal of Migration and Border Studies, Vol. 4, Nos. 1/2 (April 2018): 71-88. DOI. (C) 2018 Inderscience Enterprises Ltd. Used with permission. 


\title{
A visible geography of invisible journeys: Central American migration and the politics of survival
}

\author{
Noelle K. Brigden \\ Marquette University Political Science Department, \\ Wehr Physics Building, Room 468, \\ P.O. Box 1881, WI 53201-1881, Milwaukee, USA \\ Email: Noelle.brigden@marquette.edu
}

\begin{abstract}
Human rights groups have called undocumented Central American migrants the 'invisible victims' of criminal violence in Mexico. However, the geography of the unauthorised migration route through Mexico is highly visible; its location, protocols and violent practices constitute common knowledge in the communities through which it cuts its path. This paper examines the visual cues of the route. Images of places, such as the trailhead, the river at the borders, the migrant shelter and the train yard, provide focal points that orient migrants to the physical terrain. These images also orient activists, providing potent symbols for political contestation in favour of migrants' rights. However, visibility attracts criminal gangs who rob, kidnap and rape migrants, and the gaze of state officials who detain and deport migrants. Thus, this paper traces how geographic icons become beacons to migrants, activists, criminal predators and state actors, and it examines the nature of information and representation under this strategic interaction. It examines how victims and perpetrators become visible to one another.
\end{abstract}

Keywords: Central American migration; transit migration; migrant journeys; transnational routes; violence; migrant vulnerability; public images; clandestinity; ethnography; geography; Mexico.

Reference to this paper should be made as follows: Brigden, N.K. (2018) 'A visible geography of invisible journeys: Central American migration and the politics of survival', Int. J. Migration and Border Studies, Vol. 4, Nos. 1/2, pp.71-88.

Biographical notes: Noelle K. Brigden is an Assistant Professor in the Department of Political Science at Marquette University and a 2017-2018 Visiting Research Fellow in the Migration Community at the Princeton Institute for International and Regional Studies.

This paper is a revised and expanded version of a paper entitled 'A visible geography of invisible journeys' presented at Association of American Geographers Annual Meeting, Chicago, 8-12 April 2015; The Workshop on Governing Migration from the Margins at the University of Waterloo and the Balsillie School for International Studies, Waterloo, Canada, 11 November 2015; The Latin American Studies Association Annual Meeting, San Juan, Puerto Rico, 27-30 May 2015; the Western Political Science Association Annual Meeting, San Diego, 29-30 March 2016. 


\section{Introduction}

In July 2014, the Mexican government initiated a revitalised 'Plan Sur' with the goal of stemming the tide of undocumented Central American migrants moving through its territory. This ambitious policing plan targets the infamous freight train that the poorest, most vulnerable migrants ride north across Mexico in their desperate bid to arrive in the USA. The Mexican government justified the crackdown as an act of protection, deterring migrants from 'putting themselves at risk' on the train (Animal Politico, 2014). Since the launch of the initiative, government checkpoints in key transit points along the route, patrols around train yards, deportations and migration raids on the trains have increased dramatically, forcing migrants to find new modes of travel. Migrants must now traverse longer segments of the route by foot through the wilderness, leaving them even more exposed to the elements and criminal predation, and sometimes taking them far from the Catholic shelters established along the train tracks to provide humanitarian relief and legal support for victims of human rights abuses. ${ }^{1}$

These changes represent yet another plot twist along an already uncertain and ever changing route north for Central American migrants. Since the drug war began to escalate in 2006, the route has been characterised by sudden and unpredictable changes in criminal codes of conduct and territorial control. New violent actors emerged, breaking with old relationships and introducing new ways of profiting from the migrant suffering (Amnesty International, 2010; Brigden, 2015; Martínez, 2010; Vogt, 2013). For example, a notorious Mexican gang, called the Zetas, pioneered the practice of kidnapping and sometimes torturing migrants to extort money from migrants' relatives in the USA. The practice of kidnapping migrants has now diffused along the route. Spies infiltrate safe havens, posing as migrants, to collect information and facilitate these crimes. Formerly trustworthy coyotes (paid guides) sometimes collaborate with these ruthless gangs of kidnappers; old relationships and social networks fail without warning (Brigden, 2015). Indeed, coyotes that do not obey the new criminal terrain bosses risk their own lives. When gangs fight for control of the route, even some established coyotes feel uncertain about whom to trust, or how, when and where to cross Mexican territory safely.

In fact, even experienced migrants and guides expressed bewilderment about the changes along the route through Mexico since the drug war intensified in 2006 (Brigden, 2015). The probability of falling victim to violence increased, while at the same time the information necessary to accurately and objectively judge this probability decreased; past relationships, protocols, codes of conduct in human smuggling markets became unmoored and no longer provided reliable cues with which to predict future events along the route (Brigden, 2015). Migration theories rooted in ideas of social capital and networks have a difficult time explaining how migrants cope with such uncertainty (Brigden, 2015). As explained by Mainwaring (2016, p.3), "network theories often present migration systems as fully formed without investigating the agency required to initiate, transform, or weaken such systems".

If the most experienced migrants and guides feel daunted by this uncertainty and violence, how do the poorest pioneers move along the route with the barest of social or financial resources at their disposal? More generally, how does anyone cope with such extraordinary violence and scarcity of information?

I argue that under these conditions the visual experience of the journey itself plays an important role for migrants navigating a violent landscape; their step-by-step engagement with a social and material terrain matters. To arrive at this insight, I draw on Lynch's 
(1960) classic work on the geographical imagination to explain the role of public images along the route. Public images, as defined by Lynch, are commonly shared mental pictures of a social landscape, rooted in a collective cultural experience and interaction within a physical terrain. I describe how these public images are both tactical resources for navigating the journey and symbolic resources for negotiating the politics of migration. Using the examples of freight trains and shelters, I explore how migrants encounter the material manifestations of these images in transit. While most observers emphasise their obvious benefits as a transport vessel or source of food and shelter, freight trains and shelters also have an informational role that is emphasised here. They have become oft relied upon public images that guide the journeys of the most vulnerable and poorest migrants along the route. Trains and shelters have become the most widely broadcast signposts for the clandestine route.

However, images of crowded trains have become emblematic of a humanitarian crisis and loss of control, and therefore used to justify further state control of migration [Brigden and Mainwaring, (2016), p.427]. In what follows, I also acknowledge that criminal predators encounter these same materials, appropriating images to locate and identify their victims. For this reason, I warn not to equate migrants' visibility with their political recognition. The public diffusion of visual information about migration tactics potentially erodes the utility of that information for crossing a hostile terrain. In conclusion, I briefly reflect on the appropriation of these images by immigrant rights activists as political symbols.

\section{Methods}

In December 2010, I visited the Catholic migrant shelter in Arriaga, Chiapas, and I revisited it in the aftermath of Plan Sur in 2015. Before the reinvigorated Plan Sur, Arriaga was an early resting place along the western migration route through southern Mexico, just before the first 100-mile freight train ride to Ixtepec, Oaxaca. ${ }^{2}$ The town's name had become synonymous with the beginning of the train route. The Central Americans I met in Arriaga had already crossed the Suchiate River at the MexicoGuatemala border. To do so, they had paid the ferrymen to board the makeshift rafts that carry untaxed contraband commerce (ranging from toilet paper to cigarettes) and daily commuters in both directions. Like so many unauthorised activities along the routes through Mexico, this extensive 'free trade' system is visible in daylight (Galemba, 2012). One only needs to look down from the official international bridge or across the banks of either side of the river to get a clear view of the ceaseless economic activity. It is not a secretive practice.

The migrants I interviewed in Arriaga had also already made a long trek along well-trodden paths through the wilderness around highway migration checkpoints. That the sole use of these trails is the evasion of migration enforcement is common knowledge, and they therefore attract many bandits and sexual predators. Some of the migrants resting in Arriaga had ridden the combi (passenger shuttle) networks. Drivers of these vans alternate between helping and harming the migrants, providing free information but often extorting exorbitant fees for transport. The majority of migrants in Arriaga had already made multiple attempts at crossing Mexico. Despite having already braved so many dangers, these migrants were still at the beginning of the long journey 
north, as they were only about 150 miles north of the Guatemala-Mexico border [Kovic and Arguelles, (2010), p.87]. They had over 1,000 miles of this gruelling travel to go.

José was the first man who agreed to an interview on an early December morning $(12 / 2 / 10) .^{3}$ I choose to relay his story here because, unlike many others that I met in Arriaga, it was his first journey north. Thus, he could not draw on any previous personal experience to envision the road ahead. He was short and thin, and his age was not obvious by looking at him. He had a large bushy black moustache that seemed out of place on a youth. His brown eyes were large and round, ringed with equally round, tired circles in the otherwise youthful skin below them. He was from Nueva Santa Rosa, Guatemala. Three of his cousins had migrated to Los Angeles, but he had no communication with them. He was the oldest sibling in his house; the four others were still studying. Hurricane Agatha destroyed the properties his parents rented, devastating his poor family. ${ }^{4}$ That was what ultimately pushed him to leave. He was travelling with four friends from the same community who had also suffered damage from the hurricane. Relying on word of mouth, the kindness of strangers and God's protection, he and his companions had travelled quickly across Mexico's southernmost state of Chiapas. They had arrived safely at the migrant shelter where I found him.

Like many Central Americans I interviewed, he and his friends understood the dangers that would confront them during their journey. From anonymous rumours, stories recounted by friends and the popular media, they had learned about the potential for raids by bandits, kidnappings for ransom that they could not afford to pay, demands for tributes paid to criminal territory bosses, robberies committed by other migrants, rapes endured by female migrants, abuses committed by Mexican officials, and deaths from exposure to the elements. But this man of humble origin demonstrated only a vague grasp of the particulars that lay before him; the social and physical geography of Mexico and the USA largely remained a mystery.

By examining how migrants, like José, navigate dangerous journeys across a shifting and unpredictable social, material and political terrain, this article contributes to our understanding of how information works (or does not work) in a human security crisis. In so doing, the argument contributes to a growing literature on the micro-dynamics of violence, bridging anthropology and the study of international relations. It builds on an ethnographic tradition in political science that seeks micro-foundations for understanding a wide variety of violent situations, ranging from genocide to labour practices. ${ }^{5}$ In so doing, an analysis of these migrant journeys reemphasises the methodological importance of what Pachirat (2013) develops as 'line of sight' ethnographic analyses for understanding violence, requiring that researchers immerse themselves in the physical context to literally see from new vantage points.

Indeed, José's journey serves to remind us of the informational importance of the visual experience of these violent situations for people who seek to survive them. Line of sight ethnographic analysis of the route reveals how José's visual experience of the journey is a tactical resource for his own survival. Furthermore, overtime the collective visual experience of the route shared by migrants becomes a strategic resource for activists who challenge state propaganda with such imagery. However, such alternative visualisations can be co-opted by the state, and like a beacon, draw unwanted attention from authorities and criminal predators alike.

With just a glance at the once bustling train yards, it is now clear that in the immediate aftermath of Plan Sur, Arriaga is no longer a staging ground for large numbers of Central American migrants in transit. Recent raids on local hotels, the train yards and 
departing trains have forced many migrants to find alternative way stations. Migrants' adaptations to this new policing environment require improvisation on the material infrastructure of the route: a leveraging of old physical and informational resources to find new trails north. With fieldwork primarily conducted before Plan Sur, but updated with a targeted research trip afterwards, this article explores how the visibility of migrants' survival strategies can both enhance the safety and simultaneously undermine the security of this vulnerable group. In other words, the paths people take and the people they can engage (whether humanitarian aid workers or for-profit smugglers) must be public enough to guide future migrants north, but publicity brings danger of criminal predation and policing. The capacity of violent criminals to exploit this visibility to prey upon migrants highlights an important point: visibility without effective political contestation, and ultimately protection, facilitates violent predation.

In total, this argument draws on 281 in-depth ethnographic interviews, conducted between 2009-2011, with Central American migrants, activists, community members and others at sites along the migration corridor across Mexico, as well as in home communities in El Salvador. During my time in Mexico, I volunteered at a Catholic migrant shelter as a participant observer. Much of my discussion of the landscape of the route draws on observations gleaned by traversing short segments of it, walking within shelter facilities and using sight cues (watching people, things and their movements), not just the oral histories collected in interviews. I conducted a handful of follow-up interviews with immigrants in the USA in 2011-2012. To monitor ongoing developments, I returned to the route in the aftermath of Plan Sur, visiting the Guatemala-Mexico border and two sites in Oaxaca (Chahuites and Ixtepec) for two weeks in December 2014 and January 2015. I re-visited sites in Oaxaca, Chiapas and Veracruz in May 2015, and again made a targeted trip in June 2016 with visits to three additional sites in Chiapas, Tabasco and Oaxaca.

I supplemented participant observation and ethnographic interviews with mapmaking workshops, conducted in El Salvador from 2009-2010. Wood (2003) used mapmaking workshops in an ethnographic analysis of the collective memory of Salvadoran peasant resistance. Building on a tradition of cognitive mapping, ${ }^{6}$ I used similar mapmaking workshops to achieve a slightly different ethnographic goal. While I also examined the construction of social memory, I sought to understand the construction of the social imagination of the route. For that reason, in two Salvadoran home communities, I asked would-be migrants to imagine and draw maps of the route they expected to travel. Returned migrants were asked to remember and draw maps of the route they had taken. 22 people completed the exercise.

The migrants' maps provide both the reason and means to rethink the nature of information under conditions of uncertainty, delving deeper into the relationship between the social imaginary and lived experience. Migrants transformed maps into artwork that conveys both their hopes and memories. Much more than representations of the natural terrain, these maps can be read as a political performance: a form of protest against immigration policies and violent crimes viewed as injustice. The mapmakers interwove the normative aspects of the social imaginary into the material practices of migration. The migrant maps often depict borders, as do official maps, but they also (and sometimes exclusively) depict symbols informed by religion, common cultural motifs, and personal encounters to protest the suffering imposed by those borders: black dollar signs dotting Mexico to show the ethical 'dirtiness' of choices that confront migrants en route, the 
daily bread offered by the hand of Jesus to explain a decision to leave home at a point of origin, a manger scene of Joseph, Mary and baby Jesus to explain the sense of homelessness and mistreatment that accompanied the journey through Tijuana, etc. This method thereby reveals the 'mental maps' that organise the perceived relationship between space and social belonging (Migdal, 2004); it shows where migrant maps self-consciously converge and diverge from the official maps that cut space into discrete nation-states. Thus, they are a way of 'seeing like a migrant' (Kyle and Siracusa, 2005). Similarly, Campos-Delgado (2017) argues that migrant maps challenge the 'cartopolitics' of migration securitisation; official depictions of the route abstract from lived experience, while migrant maps humanise journeys across terrain, imbuing them with meaning. I argue that it is no coincidence that the themes and images conveyed in the maps echo popular media and political symbols ${ }^{7}$, such as 'la Bestia' and the Bible, harnessed by activists to delegitimise borders. These maps offer a normative orientation to the migration route, not just a geographical orientation.

Cartography, as a form of surveillance, augments the power of the state administrative apparatus [Harley, (1989), p.12; Scott, 1998]. As policing tools, state officials use maps in their daily planning and implementation of border control and immigration policies. As propaganda, maps nationalise territory, naturalise borders, and thereby reinforce the legitimacy of state control over human movement (Black, 1997; Harley, 1989). Finally, as bureaucratic artefacts, state maps justify expenditure and express efficiency. Maps represent one form of political visualisation, produced by states to interact with illegal border crossers and project images of control (or loss of control) to a public audience [Mainwaring and Brigden, (2016), p.248; Van Schendel, (1995), p.42].

In this sense, the migrant maps and the images they convey may be understood as a counter-mapping project. ${ }^{8}$ Maps that illustrate the dangerous route through Mexico, as opposed myopically focusing on the borders, shift public vision from the periphery to the borderlands within. The form of the migrant maps, in particular, often privileges notions of place over an abstract space bounded by linear borders. Several migrants did not depict the journey as spatial, choosing instead to highlight the primacy of a universal morality and personal experience over territory. They thereby offer a non-territorial matrix to understand political authority and responsibility. In so far that these images make claims to a higher moral authority of universal human rights and divine will, they overtly challenge the legitimacy of the state to exclude foreigners. Of course, alone the 'legibility' of migration experience via counter-mapping does not automatically challenge national authority to exclude migrants from territory, and it must be embedded in a larger political narrative and struggle. Nevertheless, maps and public images provide signposts for politics, not only signposts for practice.

\section{Public images: signposts for the underground}

Migrants rely on human guides, i.e., coyotes, to negotiate the spatial and social geography of the journey. Migrants who cannot afford guides rely on word of mouth from other migrants and more experienced travel companions, and they learn how to travel north by travelling and encountering new objects and terrain. Migrants converge en masse in freight train yards in southern Mexico as a site for both information and transportation.

To navigate their journeys in this way, the poorest migrants take visual cues from their surroundings. ${ }^{9}$ Images of places, such as the trailhead, the river at the borders, the 
migrant shelter and the train yard, provide focal points that orient migrants to the physical terrain. When rendered memorable by their differentiation from other terrains or symbolic importance, such landscape features, such as train tracks or the rivers at borders, guide people great distances. They also provide a basis for common knowledge of the location of migratory routes. The terrain of the route is thus hidden from official view, but easily found by searching for access points defined by public images. ${ }^{10}$ Material cues provide flags, such as a trailhead that leads migrants north around a checkpoint. Popular culture provides flags too, such as the train that has become part of the folklore in song, stories and movies about the journey. As these symbols proliferate and become recognisable, they mark the existence of clandestine social spaces.

These 'public images' emerge from the interplay between a transit political economy, transnational imaginary and the material space traversed by generations of migrants. ${ }^{11}$ The broad publicity of these images points to widespread social participation in unauthorised migration, including the complacency or collaboration of Mexican citizens and corrupt officials along the routes [Casillas, (2007), p.40]. The images become visible to the general public, in part, because migrants interact with citizens during their journey, conducting a variety of social and economic transactions that diffuse information. Once such images are public, they flag the location of the route and open informational entry points to the underground flow for newcomers, whether migrants or potential criminal predators.

Before José left Guatemala, he consulted only two people. Neither one was a parent. His father had died eight years ago, and his mother lived far from him in Esquintla, a city on the western side of the country. He did not ask her. Nor did he talk to his cousins who had travelled the route before him. Instead, a female cousin who stayed behind in Guatemala warned him of the risks: assaults, kidnappings, murders, and the possibility of falling from the train. Her advice was simply to "be careful". A friend in the USA agreed to help, but his friend's advice was almost as vague: "Take care of yourself. Do not talk to unknown people. Do not sleep just anywhere. Do not walk in the mountains because of snakes and thieves". Of course, José had to do these things anyway, even though he had not planned to. He began the journey by asking God for protection, "because it is very complicated to get started with advice like that". Then he and his companions went in search of the train. When discovered en route, these public images indicate openings where further information about clandestine practice may surface. Two of these signposts have particular importance for José and the poorest migrants travelling north: trains and shelters.

\section{The freight train: a compass}

The train is strictly for freight, not passengers. In the 1990s, the Mexican government suspended passenger service, leaving only freight trains, except for a handful of short novelty lines for tourists and the Mexico City commuter system. At that time, the government granted concessions to a handful of private companies for the continuation of freight service. Migrants ride the freight trains like hobos. Until 2005, this route began in Tapachula, Chiapas, but that segment of the route suffered damages in Hurricane Stan and has been indefinitely suspended. Migrants lamented the closure of this southernmost segment, because crossing Chiapas now requires some combination of extensive hiking 
on dangerous trails and expensive passenger transport. Since 2014, the immigration crackdown of Plan Sur has made riding the train increasingly difficult, and crossing Oaxaca also requires extensive hiking on dangerous trails. For migrants without financial resources for expensive smugglers or passenger transport, the journey into the interior of Mexico can take weeks on foot. This time on the route leaves them more vulnerable to criminal predation.

José left home with only a vague notion of geography. ${ }^{12}$ However, he found the train yards in southern Mexico. He knew that the freight trains would carry him in the right direction. In that sense, the train yard served as an entry port to a clandestine terrain, where word-of-mouth and the physical space itself can lead a migrant to the US border. The freight train was not only an inexpensive transport vehicle; its tracks and equipment were and remains a conduit for information. ${ }^{13}$ For example, the colours and markings of the engines signal the destinations of the trains. If the train broke down or migrants had to flee into the wilderness to escape a migration raid, scattering and hiding among the bushes, they would regroup around the tracks as a focal point, using the steel rails to guide their long walk to the next shelter. Now, much of the hike through southern Mexico follows the old tracks, relying on the train tracks to locate the shelters. Simply put, the train is a compass.

It is not surprising that the train has come to serve as a focal point for migrants, particularly near the beginning of the route through Mexico. Walters (2015) observes that vehicles play a pivotal role in the political drama of migration, as prominent settings for mobility and the contestation of borders. In Lynch's (1960, p.9) words, the train have a high level of imageability:

\begin{abstract}
"That quality in a physical object which gives it a high probability of evoking a strong image in any given observer. It is that shape, colour, or arrangement which facilitates the making of vividly identified, powerfully structured, highly useful images of the environment."
\end{abstract}

The source of the train's eminent imageability is twofold: material and symbolic. Beginning in the 1990s and intensifying with the first iteration of Plan Sur in 2001, the proliferation of highway migration checkpoints pushed an increasing number of migrants to the trains, generating a bottleneck for unauthorised traffic along the tracks (Casillas, 2007). The poorest migrants could not afford to pay smugglers or bribe corrupt officials who stop the bus.

The location and sporadic tempo of train service, combined with the increasing numbers of migrants converging on the train, created large crowds of migrants across southern Mexico. From Chiapas through Veracruz, trains run relatively infrequently and unpredictably, as a result of a schedule dictated by the weather, wear on the aging rail network and the logistical needs of the patchwork of subsidiaries of the major railway companies. This unpredictability often produces a backlog of migrant hopefuls loitering around train yards. ${ }^{14}$ The presence of these crowds illuminates the way forward, and sudden movements in the crowd signal either danger or the impending departure of a locomotive. In this southern zone, the tracks begin in Tenosique, Tabasco in the east and Arriaga, Chiapas in the west, merging in Veracruz and moving migrants to the outskirts of Mexico City before dividing into many alternative routes north. While such large crowds have become less common in the aftermath of the 2014-present crackdown, the social memory of the train as a conduit for this information lingers; migrants still converge on the tracks and train yards to search for information. The train-riding era has 
left a material and symbolic legacy for the time being, one that would likely be fully revived were such intense immigration policing to pause.

In contrast to those in the south, trains in the northern half of the country run faster, more frequently and in more directions, thereby dispersing the crowds of migrants. ${ }^{15}$ Because of this dispersion, the train began to lose its imageability in the north. As the journey progresses, this class of migrants relies increasingly on information transmitted by word-of-mouth or paid guides. If intense immigration policing persists along the southern section of the train route, it too will likely eventually take on these qualities.

The symbolism of 'the beast', as the train has become known colloquially, provokes strong emotions. In the past, the desert at the US-Mexico border represented the most potent popular image of suffering during the journey. Today, the image of suffering is most commonly associated with the train, which dominates popular media and folklore in Central America. Legends about the terrible accidents and assaults that stalk its rails circulate widely. Images of people with severed limbs lost to these accidents are commonplace in the Central American press. Ironically, these harrowing stories orient Central American to the train, making the image of the locomotive and its relationship to migration recognisable, rather than scaring people away. Thus, as immigration policing and danger intensify along routes far from borders, the train has taken a central place in the social imagination of the route, thereby becoming a useful, albeit dangerous, arrow that points people north.

\section{Shelters: informational oases}

Catholic migrant shelters form an integral part of the 'sacred geography' of the route (Hagan, 2008). They are the most common places that migrants turn to for help. In these places, migrants can learn about the latest security threats, receive updates about police movements, discover alternative routes north, find out about job opportunities, watch and mimic tactics employed by other migrants, ascertain their legal rights and form new relationships with potential travel companions and smugglers. In contemplative moments, migrants receive spiritual support, and they listen to arguments by clergy and activists about their ethical obligations and rights.

The shelters, as spaces protected by their moral authority, political power and physical barriers (sometimes including video monitoring systems, security guards, cement walls, etc.), usually offer sufficient physical security to facilitate conversations among strangers without an immediate fear of assault or apprehension by authorities. With some notable exceptions, people remain safe until they leave the sanctity of the shelter grounds. This modicum of security contributes to a relatively relaxed atmosphere, when compared to the train yards at night, and permits more information to surface. In this way, a migrant shelter becomes an oasis where information can surface along the route.

Nevertheless, nowhere along the route is the double-edged nature of information more apparent than at migrant shelters. The shelters are also an informational resource for a variety of other actors, some of them with nefarious intent. Spies, known as rateros, enter the shelters to retrieve information about migrants for kidnappers. More specifically, spies seek to identify who received money through Western Union, the phone numbers of relatives in the USA, the travel plans of migrants, and the presence of 
members of competing gangs. Recruiters for smugglers also enter the shelter, hoping to advertise their services to potential clients.

Shelter personnel are well aware of these problems. In January 2011, during a period of political activism in response to a mass kidnapping near Chahuites, Oaxaca on 16 December 2010, criminals entered the shelter grounds in Ixtepec, Oaxaca. They did not disguise their intent to intimidate the staff, boasting of the intelligence they had gathered about the volunteers working there. These men allegedly found the shelter priest resting in his hammock and warned him: "Do you know why we do not kill you? Because if we kill you, they are going to close the shelter and it is going to be more difficult to find the undocumented. However, with the shelter, you get them together for us". ${ }^{16}$ Thus, these places become the site of a struggle over information, as migrants and violent criminals attempt to conceal their personal data and identities from one another. Indeed, the shelters provide a variety of services to migrants, but information is the single-most important resource and danger that migrants confront there. Like any other oasis, shelters draw predators.

How do shelters become informational oases? The activities within the shelters facilitate information flows, leaving a material trace that future migrants encounter as knowledge-based artefacts ${ }^{17}$. The shelters have fixed locations shaped by migration practice. Importantly, the shelters' security protocols can ensure safety for migrants to gather, but only at the expense of their informational value to migrants. In other words, attempts to enforce security protocols have the unintended consequence of spatially isolating migrants from potential predators and limiting their movement, thereby creating potential barriers to information flows. Finally, political contestation protects the space of the shelter. The preservation of the shelter as a space requires more than information flows visible at the level of clandestine practice; it requires public representation. Institutionalised religion projects moral authority and represents migrants in Mexican society to achieve public recognition, not only visibility. Nevertheless, the paradox of public images as beacons for predators, as well as migrants, continues to haunt these 'safe spaces' along the route.

Firstly, shelter staff will sometimes organise information sessions for migrants to warn them of the dangers ahead. These briefings are sometimes part of the registration process. Staff may also give some carefully guarded advice to the migrants they perceive as the most vulnerable to abuse, such as women travelling with small children. Therefore, shelter staff selects the migrants and circumstances under which they share that information carefully. When migrants successfully pass along the route, they relay the information back to the shelter staff by telephone.

Of course, most of the information passes without intent. People simply tell yarns to kill time. They also eavesdrop on gossip. The main source of entertainment for the poorest migrants is the conversation and reality drama that unfold in shelters. By participating in this drama, migrants come to understand the route and its inhabitants.

Migrants also use the shelters to communicate with family and friends in the USA and Central America via telephone or, where available, the internet. Some shelters offer free phone calls, while others provide public phones to be used with pre-paid cards. In this manner, the shelters become a node for transnational informational (and financial) exchanges. Furthermore, family members of migrants from Central America often contact shelters in search of missing persons.

These attempts to access information at the shelter leave a material trace, which provides signposts for future migrants. The sad yellowing posters of missing persons 
flapped in the breeze of a doorway in the shelter in Saltillo. The dirt yard in Ixtepec was littered with phone cards. On the walls of the now defunct shelter in San Luis Potosi, migrants had lovingly inscribed the addresses of shelters in Mexico and the USA, as well as the contact information for the Denver day labour centre, Centro Humanitario. They also left behind artwork, messages of encouragement and their own names.

The semiotics of murals in shelters is unambiguous. The artwork created by migrants and activists challenges the legitimacy of immigration enforcement. These scenes empathise with the plight of migrants, compelled to follow a difficult path in Jesus' footsteps. They often depict the promised cities of the north, shining and waiting for the deserving migrant who endures and completes the journey. The messages are decidedly cosmopolitan in their appeal to a larger understanding of the Americas and the globe. The messages show footsteps that trespass borders, the destruction of borders or simply the removal borders altogether. The artwork depicts the suffering of the migrants through religious imagery with coffins or a cross. Finally, they may contain scenes that vilify immigration policing, placing state personnel in opposition to Jesus. In fact, such artwork is not limited to the walls of migrant shelters. The murals even co-opt the very spaces intended for immigration enforcement. Like the West German side of the Berlin Wall, the Mexican side of the US border wall has become the medium for expressing frustration with government policies that separate transnational communities and put migrants in danger [Sheridan, (2009), pp.111-137].

However, the moral imperative and normative power conveyed by the murals and other activism within the shelter are insufficient to keep all covert predators away from the shelters. Kidnappers covet information about who is making phone calls to the USA. This information is used as an indicator of which victims can pay handsome ransoms. They seek to identify these phone numbers for extortion rackets. Smugglers solicit potential clients and may also infiltrate the shelters posing as migrants. While they rarely openly enter shelter grounds, bandits and corrupt police seeking bribes often stalk the routes to and from these facilities.

Second, the locations of shelters are relatively fixed and shaped by sustained migration practice. The physical layout of the shelters differs dramatically from one to the next, depending on the unique history of the place. Often the struggle over information and security drives physical changes to the shelters, causing staff to erect large cement walls, gates, video surveillance and other precautions. Thus, the potential for violence against migrants shapes the material contours of shelters. In turn, these material contours shape the information available to migrants by segregating and isolating some populations, and changing patterns of movement within (as well as into/from) the shelters.

The shelter layout inevitably adapts to new resources, threats and needs over time. Some shelters look like large converted homes. Others look like secure compounds. Some sprout from congregational initiatives, growing as addendums to existing buildings owned by the church. NGOs may make large donations to shelters to enable specific projects, like dealing with a pressing sanitation or security issue, depending on their own reading of priorities. Skilled Central American masons or electricians occasionally take time from their journeys north to contribute, either by earning wages or volunteering. Migrants themselves have built many of these structures piecemeal over time, and the compounds often expand in a makeshift manner as financial resources, human capital and construction materials become available. The rules and regulations of shelters are also 
often products of experience, changing and adapting as shelter staff confront new dilemmas and improvise upon old ways of doing business. In the aftermath of the intensification of Plan Sur in 2014, some established shelters have seen the human flow turned away from them by police checkpoints that make migrants' arrival there difficult. At least one shelter has responded by setting up a satellite facility in a new location on the route. In this sense, the social and material structure of the shelters emerges from practice, an unintended collective residue of the actions of individual migrants.

In turn, the social and material structure of the shelter shapes migration practice. New shelters attract migrants, changing the course of the human flow. The regulation and physical layout of the place shapes the information available to migrants during their journey. There is a trade-off between physical security and the flow of information through the shelter. Physical security requires screening processes for selective entry of migrants deemed to be unthreatening to their potential travel companions, a schedule for entry/exit that promotes control, and segregation of sleeping areas by gender. The more isolated and selective the shelter becomes, the less opportunity for infiltration by criminal gangs.

However, the regulation of movement in and out of the shelter comes with a steep price for migrants: they become less capable of learning about and adapting to changes in the route. For example, shelters often segregate Mexicans and Central American to minimise opportunities for recruitment by smugglers and infiltration by kidnappers. This segregation by nationality also decreases the information available to migrants. It isolates them from the larger community. Within their grounds, shelters also often segregate sleeping areas by gender, because sexual assault is so common. However, the segregation of men and women decreases the information available to the female minority by cutting them off from gossip at night. Indeed, in an extreme case, men and women are locked behind bars in separate wings of the facility at a regulated hour. Shelters often deny entry to repeat customers, who come under suspicion as smugglers or spies. However, in so doing, the shelter excludes the most experienced migrants from sharing their stories with others. In the most regulated shelters, migrants cannot leave to go to the train when they receive information about its immediate departure. They cannot leave to make travel arrangements and re-enter to wait. Finally, and most importantly, migrants may choose not to enter the shelter for fear of missing vital information about the movement of the trains:

\footnotetext{
"Because of the irregular schedule of the trains, there is a need to sleep in the vias and that is where the danger of the attacks comes from (interview with Guatemalan migrant, Ixtepec, 14 May 2011)."
}

At night, the train yards, or vias, are extraordinarily dangerous places, and it is a measure of the high value of this information to migrants that they would risk sleeping there to receive it. Thus, the regulation of movement in and out of the shelter is an important security consideration. Movement must be monitored to prevent kidnappings out of the shelter and to prevent the smuggling of guns and drugs into the shelters. This is required in order to maintain the safety of the shelter, and that safety is keys for the survival of an informational oasis. However, too much regulation also undermines the informational utility of the place. These security regulations undermine the flow of information through the shelter, and ultimately erode the human security of migrants.

Finally, institutionalised religion facilitates the shelter's visibility under these quasi-legal conditions, deterring intervention by federal Mexican authorities and 
deterring the most flagrant assaults by organised criminal gangs. In the 1980s, Catholic shelters mostly clustered in the northern border zone, the most dangerous place for migrants at that time (Hagan, 2008). At first, these shelters provided a respite for weary Mexican travellers. As the refugee flow from Central America accelerated, the shelters became the front line for human rights activism on behalf of Central American fleeing political violence. During the 1990s, when US border patrol effectively closed the migration corridor through Tijuana-San Diego and deportations intensified, some shelters in the northern border zone began to cater to Mexicans deported back. These Mexican migrants sometimes returned penniless and became stranded in frontier towns far from their homes. Mexican and Central American activists and humanitarian workers, like the sister sanctuary movement in the USA, drew inspiration from liberation theology and their broader Christian faith (García, 2006; Hagan, 2008).

In the 2000s, awareness of the horrors of the journey from Central America spread, and the number of migrant shelters along the route multiplied despite the fact that they were not exactly legal. In 2008, the Mexican Supreme Court decriminalised humanitarian aid to migrants, which had not previously been clearly distinguished from smuggling under article 77 of the population law. While humanitarian workers and activists still report some harassment from police, this ruling facilitated the expansion and further institutionalisation of the shelter system.

By 2012, there were approximately 54 shelters from Guatemala to the US border. Any estimate of their presence is complicated by the fact that new shelters periodically open and others close. Many of them, however, congregate in the most visible corridors of the route serving the poorest and most vulnerable migrants who travel along the train tracks or linger at the borders. Catholic faith has inspired both clergy and laypeople to organise most of these shelters, but they serve migrants from any religion. Most of them are loosely networked through the church, but not funded by it. While the relationship with the surrounding community may be friendly or hostile, the shelters become a hub of local economic activity. For this reason, Vogt (2012, p.39) conceptualises them as depots along the unauthorised route, i.e., places of constant coming and going through which migrants are "transformed into commodities where they were traded, bought, sold and distributed". As such, the shelter is a hub in the clandestine political economy, but protected as a space by the moral authority of the church.

Outside of shelters, there are also informal encampments built by migrants. During exceptional moments, the Mexican federal government has provided temporary migrant camps, most recently during a major backlog of migrants in Veracruz in the summer of 2012 caused by the cessation of train service following a derailment (Barranco, 2012). However, these informal encampments and ad hoc camps lack the moral and political power of the migrant shelter system. The moral authority of the Catholic Church in Mexico creates a political space for particularly open informational oases. In an oft-cited poll conducted by Consulta Mitofsky, Mexicans have consistently ranked universities and the Catholic Church as the least corrupt institutions in Mexican society (Archibald, 2012). Most Mexicans are Catholic, and even criminals fear for their immortal soul. Thus, accusations that priests participate in smuggling do not generally persuade the public, protecting them against criminal charges for trafficking. The institutional and normative power of the Catholic Church enhances the power of individual priests to maintain these facilities despite threat from both governments and criminals. 
Shelters that project information of the route to transnational human rights networks provoke additional security guarantees from politicians, and they may receive material resources for surveillance, guards and cement walls. Thus, shelters play a vital role in political contestation for migrants' rights. They provide an access point to the underground for the general public. A multinational cadre of journalists, human rights investigators, researchers and activists arrive at the shelters daily to take testimonies from the migrants that congregate there. For this reason, the shelters are not only a platform for migration. Shelters also become a platform for the projection of information necessary for national and international political activism.

\section{Conclusions: toward a politics of migrant navigation}

The micro-politics of migrant navigation has two dimensions. First, at a tactical level, visibility of the route cuts two ways, producing vulnerability and informational resources for migrants. Second, at a political level, visibility provides a first step to public recognition and demands for rights. Public images function at both tactical and political levels, marking sites of the underground economy for participants and providing the symbols that represent that activity to the larger political audience. The tactical and political worlds become one social reality along the route.

It is no coincidence that activists appropriate these same public images to locate migrant victims of crime and gather their testimonies. Nor is it a coincidence that academics and journalists travel to migrant shelters or board freight trains to understand human security. Indeed, the argument developed in this article suggests that such 'line of sight' methods, such as participant observation and ethnographic immersion, are necessary to understand the full range of survival resources available to people in violent situations.

The fact that tactical and political worlds become one social reality should both encourage and caution researchers engaged with these human security dilemmas. On the one hand, political visibility is essential strategically for activists and the larger population of migrants in transit across Mexico, and research can enhance this agenda. On the other hand, tactical invisibility is essential for migrants traversing a dangerous terrain, and research that renders routes across this terrain visible potentially exposes migrants to predators, whether criminals or the state.

Thus, the same signposts that guide migrants also guide activism and research around clandestine migration, and informational tensions also haunt activism and research around vulnerable clandestine populations. In particular, the imagery of the train as 'the Beast' offers clear illustration of desperation and sacrifice of the hundreds of thousands of Central American who attempt the journey each year and, as such, has become a rallying cry against the abuse of migrants in transit. Walters (2015) suggests that, "vehicles can be mobilised in counter-narratives where they are means to articulate a politics of hope and injustice as well [as risk and suffering]". Indeed, activists periodically board the train as an act of protest. Human rights activists reproduce such public images to raise awareness of the plight of migrants and heighten a sense of humanitarian crisis; they explicitly seek to make 'invisible victims' visible. As explained by Kovic and Arguelles (2010, p.94), "the coexistence of visibility and invisibility of blinding and being a blind spot, applies to Central American transmigrants and other marginalised groups. To make someone invisible is an act of violence...yet members of 
marginalised groups are also hyper-visible; that is, in being defined as outsiders, they stand out and are perceived as being out of place". The images promoted by activists attempt to both challenge the invisibility of migrants to the protections of the law and the visibility of migrants as other.

With these goals in mind, visualisations of the route enabled by participant observation and mapmaking offer a path forward for understanding and advocating on behalf of vulnerable populations caught in violent situations. However, it is a path that presents an informational paradox and ethical dilemma that must be carefully navigated. These images overtly question the legitimacy of the state to exclude foreigners. For this reason, such images can also signal to state agencies where it can best neutralise clandestine routes to project control. Visual information, whether in the tactical environment confronted by migrants during individual journeys or the strategic environment confronted by activists during political contestation, has a dual life as both potential resource and danger.

\section{Acknowledgements}

This work received and support from the National Science Foundation Dissertation Research Improvement Grant in Sociology, the Fulbright-Garcia Robles Scholarship, the Social Science Research Council International Dissertation Research Fellowship, the Bucerius PhD Scholarship Program in Migration Studies 'Settling Into Motion' from the Zeit-Stiftung, the Institute for Social Science, the Einaudi Center for International Studies at Cornell University, and a post-doctoral fellowship at the Watson Institute for International Studies at Brown University. I would like to thank Peter Katzenstein, Richard Bensel, Christopher Way, Kenneth Roberts, Michael Jones-Correa, Cetta Mainwaring and Margaret Walton-Roberts for insightful feedback on drafts of this article.

\section{References}

Amnesty International (2010) Invisible Victims, Migrants on the Move in Mexico, Amnesty International Publications, London.

Animal Politico (2014) Estas son las principals acciones de la Programa Frontera Sur para proteger a los migrantes [online] http://www.animalpolitico.com/2014/08/estas-son-lasprincipales-acciones-del-programa-frontera-sur-para-proteger-migrantes/ (accessed 19 October 2015).

Archibald, R.C. (2012) 'Adding to the unease of a drug war alliance', New York Times, p.A4.

Autessere, S. (2010) The Trouble with the Congo: Local Violence and the Failure of International Peacebuilding, Cambridge University Press, Cambridge.

Barranco, R. (2012) 'Derailment, crowd 'migrantes, 'encallados' en Veracruz', El Universal [online] http://www.eluniversal.com.mx/estados/86747.html (accessed 19 July 2013).

Black, J. (1997) Maps and Politics, University of Chicago Press, Chicago.

Brigden, N.K. (2015) 'Transnational journeys and the limits of hometown resources: Salvadoran migration in uncertain times', Migration Studies, Vol. 3, No. 2, pp.241-259.

Brigden, N. and Mainwaring C. (2016) 'Matryoshka journeys: Im/mobility during migration', Geopolitics, Vol. 21, No. 2, pp.407-434. 
Campos-Delgado, A. (2017) Counter-mapping Migration: Irregular Migrants' Stories through Cognitive Mapping, Unpublished Manuscript.

Casillas, R.R. (2007) Una Vida Discreta, Fugaz y Anónima: Los Centroamericanos Transmigrantes en Mexico, CNDH, Mexico City.

Coutin, S.B. (2005) 'Being en route', American Anthropologist, Vol. 107, No. 2, pp.195-206.

De León, J. (2015) The Land of Open Graves: Living and Dying on the Migrant Trail, University of California Press, Berkeley.

Fenster, T. (2009) 'Cognitive temporal mapping: the three steps method in urban planning', Planning Theory \& Practice, Vol. 10, No. 4, pp.479-498.

Fuji, L.A. (2009) Killing Neighbors: Webs of Violence in Rwanda, Cornell University Press, Ithaca.

Galemba, R. (2012) 'Corn is food, not contraband: the right to 'free trade' at the Mexico-Guatemala border', American Ethnologist, Vol. 39 No. 4, pp.716-734.

García, M.C. (2006) Seeking Refuge: Central American Migration to Mexico, the United States and Canada, University of California Press, Berkeley.

Hagan, J.M. (2008) Migration Miracle: Faith, Hope and Meaning on the Undocumented Journey, Harvard University Press, Cambridge.

Harley, J.B. (1989) 'Deconstructing the map', Cartographica, Vol. 26, No. 2, pp.1-20.

Kovic, C. and Arguelles, F. (2010) 'The violence of security: central American migrants crossing Mexico's southern border', Anthropology Now, Vol. 2, No. 1, pp.87-97.

Kyle, D. and Siracusa, C.A. (2005) 'Seeing the state like a migrant: why so many non-criminals break immigration laws', in van Schendel, W. and Abraham, I. (Eds.): Illicit Flows and Criminal Things: States, Borders, and the other Side of Globalization, pp.153-176, Indiana University Press, Bloomington.

Lynch, K. (1960) The Image of the City, MIT Press, Cambridge.

Mainwaring, C. (2016) 'Migrant agency: negotiating borders and migration controls', Migration Studies, pp.1-20.

Mainwaring, C. and Brigden, N. (2016) 'Beyond the border: clandestine migration journey', Geopolitics, Vol. 21, No. 2, pp.243-62.

Martínez, O. (2010) Los Migrantes Que No Importan: En el camino con los centroamericanos indocumentados en Mexico, Icaria, San Salvador.

Migdal, J.S. (2004) 'Mental maps and virtual checkpoints: struggles to construct and maintain state and social boundaries', in Migdal, J.S. (Ed.): Boundaries and Belonging: States and Societies in the Struggle to Shape Identities and Local Practices, pp.3-23, Cambridge University Press, Cambridge.

Pachirat, T. (2013) Every Twelve Seconds: Industrialized Slaughter and the Politics of Sight, Yale University Press, New Haven.

Powell, K. (2010) 'Making sense of place: mapping as a multisensory research method', Qualitative Inquiry, Vol. 20, No. 10, pp.1-17.

Ruiz Parra, E. (2011) Solalinde' Gatopardo [online] http://www.gatopardo.com/ReportajesGP. php?R=104 (accessed 19 July 2013).

Scott, J.C. (1987) Weapons of the Weak: Everyday Forms of Peasant Resistance, Yale University Press, New Haven.

Scott, J.C. (1998.) Seeing Like a State: how Certain Schemes to Improve the Human Condition Have Failed, Yale University Press, New Haven.

Seyer-Ochi, I. (2006) 'Lived landscapes of the fillmore', in Dearborn Spindler, G. and Hammond, L. (Eds.): Innovations in Educational Ethnography: Theories, Methods and Results, Lawrence Earlbaum Associates, Mahwah.

Sheridan, L.M. (2009) I Know It's Dangerous: Why Mexicans Risk Their Lives to Cross the Border, University of Arizona Press, Tucson. 
Van Schendel, W. (1995) 'Spaces of engagement: how borderlands, illicit flows, and territorial states interlock', in van Schendel, W. and Abraham, I. (Eds.): Illicit Flows and Criminal Things: States, Borders and the Other Side of Globalization, pp.38-68, Indiana University Press, Bloomington.

Vogt, W. (2012) Ruptured Journeys, Ruptured Lives: Central American Migration, Transnational Violence, and Hope in Southern Mexico, Unpublished PhD thesis, School of Anthropology, University of Arizona, Tucson, USA.

Vogt, W. (2013) 'Crossing Mexico: structural violence and the commodification of undocumented central American migrants', American Ethnologist, Vol. 40, No. 4, pp.764-780.

Walters, W. (2015) 'Migration, vehicles, and politics: three theses on viapolitics', European Journal of Social Theory, Vol. 18, No. 4, pp.469-488.

Wood, E.J. (2003) Insurgent Collective Action and Civil War in El Salvador, Cambridge University Press, Cambridge.

\section{Notes}

1 A system of over 60 shelters now lines the migration route across Mexico. As will be discussed, most of these shelters have some affiliation with the Catholic Church or espouse some Catholic inspiration for their work. However, they are diverse entities with different levels of institutionalisation and resources, offering a variety of services ranging from daytime soup kitchens to legal support and overnight stays, and maintaining varying linkages to religious orders or local congregations.

2 See also Kovic and Arguelles (2010, p.87).

3 The name José is a pseudonym.

4 A volcanic eruption followed by tropical storm Agatha in May 2010 hit the municipality of Nueva Santa Rosa, Santa Rosa very hard. This dual disaster displaced thousands of people and resulted in the loss of many homes.

5 See for example, Autessere (2010), Fuji (2009), Pachirat (2013), Scott (1987) and Wood (2003).

6 See for example, Fenster (2009), Lynch (1960), Powell (2010) and Seyer-Ochi (2006).

7 I discuss the origins of public images within a transit political economy, transnational imaginary and migration practice in greater depth elsewhere.

8 In a similar vein, Campos-Delgado (2017) also frames migrant maps as a counter-mapping project.

9 These visual cues can also be important to migrants unexpectedly separated from their high-end smugglers.

10 In this vein, Coutin (2005, p.198) defines clandestine as 'hidden but known'.

11 Similarly, Lynch (1960, p.7) argues that public images "might be expected to appear in the interaction of a single physical reality, a common culture, and a basic physiological nature".

12 For example, he mistakenly identified his hometown as located in the northern part of Guatemala. Nueva Santa Rosa is located approximately 70 miles south of Guatemala City.

13 According to migrants and human rights activists, the price of riding the freight train has been increasing since 2011, as the street gangs are again attempting to extend and deepen their control of the train route. Their capacity to extort boarding fees, in particular along the eastern route through Tenosique, has increased. Migrants and smugglers who cannot pay may be thrown from the train. The price of riding the train remains high, despite the police raids that frequently disrupt train journeys.

14 The most dramatic of these backlogs in recent history occurred in Veracruz in June and July 2012 when hundreds (or thousands, depending on whose estimate) of migrants became stranded without resources after a derailment suspended freight train service (Barranco, 2012). 
15 Private security on most trains can be bribed for passage, but some migrants know better than to try to board the most freshly painted engines that connect Saltillo with auto dealers in the USA; the security on that line is too effective for migrants to ride in the open.

16 Quoted in Ruiz Parra (2011); translation of quote is mine. Vogt (2012, p.270) repeats a very similar quote from a shelter priest whose life was spared because a street gang did not want the shelter to close. Vogt also describes the ironic symbiosis between migrant shelters and the gangs who prey upon migrants. Her purpose in describing this contradiction is to examine how structural violence undermines solidarity and leads to the corruption of safe spaces by violent actors.

17 For a discussion of how migration practice intentionally and unintentionally shapes objects and material terrain, see De León (2015). 